\title{
Changes in the intragastric distribution of Helicobacter pylori during treatment with omeprazole
}

\author{
R P H Logan, M M Walker, J J Misiewicz, P A Gummett, Q N Karim, J H Baron
}

\begin{abstract}
Omeprazole is a powerful inhibitor of gastric acid and may suppress Helicobacter pylori by effecting the pKa of $H$ pylori urease, by altering the pattern of infection, or by promoting overgrowth of other bacteria. At routine endoscopy $H$ pylori was detected by histology and culture before and after four weeks' treatment with omeprazole, $40 \mathrm{mg}$ each morning. $A{ }^{13} \mathrm{C}$-urea breath test was also done at $t=0,2,4$, and 6 weeks. Thirty nine patients with duodenal ulcer $(n=25)$ or reflux oesophagitis $(n=14)$ were studied, of whom 29 of 39 had $H$ pylori infection. During omeprazole treatment, ${ }^{13} \mathrm{C}$-urea breath test values fell significantly - mean (SEM) values before treatment and at four weeks were $23.0(2 \cdot 1)$ and $15.5(2 \cdot 7)$ per mil respectively, $\mathbf{p}<0 \cdot 001$. Before treatment $H$ pylori was seen in 28 of 29 antral, 29 of 29 corpus, and 28 of 29 fundic biopsy specimens. After four weeks of omeprazole treatment, the histological density of $H$ pylori in the antrum and corpus was reduced $(p<0.001)$, while that in the fundus was increased. The migration of $H$ pylori from the antrum to the fundus was associated with a corresponding decrease in the activity of antral gastritis. $H$ pylori was not seen in antral biopsy specimens from 12 of 29 patients whose median excess $\delta{ }^{13} \mathrm{CO}_{2}$ excretion fell from 23.0 to 9.9 per mil. In the body mucosa, 26 of 29 specimens were still positive for $H$ pylori and there was no significant change in the gastritis type. Two weeks after finishing treatment, the mean (SEM) excess $\delta{ }^{13} \mathrm{CO}_{2}$ excretion returned to levels before treatment. Omeprazole decreases antral $H$ pylori colonisation but increases that in the fundus. The changes in the intragastric distribution of the organism are associated with concomitant changes in the activity of gastritis and are matched by a progressive fall in the excretion of $\delta{ }^{13} \mathrm{CO}_{2}$.

(Gut 1995; 36: 12-16)
\end{abstract}

Keywords: Helicobacter pylori, intragastric distribution, omeprazole, ${ }^{13} \mathrm{C}$-urea breath test.
Helicobacter pylori causes non-autoimmune gastritis ${ }^{1}$ and is an important factor in the aetiology of recurrent duodenal ulcer disease. ${ }^{23}$ $H$ pylori colonises only gastric type epithelium. Its powerful urease activity is probably essential for colonisation and the base produced by urease may protect the organism from gastric acid. ${ }^{45}$ Omeprazole inhibits $\mathrm{H}+/ \mathrm{K}+$ ATPase, and $40 \mathrm{mg}$ can suppress over $80 \%$ of gastric acid secretion. ${ }^{6}$ Initial reports of the effect of omeprazole on $H$ pylori were inconclusive. ${ }^{78}$ Although eradication has been claimed in some reports, ${ }^{8-10} H$ pylori status was assessed prematurely and on antral biopsy specimens alone. More recent reports using either the ${ }^{13} \mathrm{C}$ or ${ }^{14} \mathrm{C}$-urea breath test suggest that omeprazole partly suppresses, but does not eradicate $H$ pylori. ${ }^{11} 12$ This prospective study examines the effect of omeprazole on the distribution and persistence of $H$ pylori within the stomach using the ${ }^{13} \mathrm{C}$-urea breath test and antral, corpus, and fundic histology.

\section{Methods}

Patients attending for routine diagnostic gastroscopy and likely to need omeprazole were invited to take part in, and give written consent to this study, which was approved by the Parkside Ethical Committee. Patients with previous gastric surgery, known bleeding diathesis, taking oral anticoagulants, or who had been treated with bismuth compounds, omeprazole, or antibiotics known to be active against $H$ pylori within the previous two months, were excluded. To determine $H$ pylori status biopsy specimens were taken from the antrum (within $2 \mathrm{~cm}$ of the pylorus, two for histology and two for microbiology), corpus (half way along greater curvature, two for histology), and fundus (two for histology).

After each examination the endoscopes were disinfected by an automatic washing machine (Olympus EW20) ${ }^{13}$ and the biopsy forceps were sterilised by autoclaving.

A ${ }^{13} \mathrm{C}$-urea breath test ${ }^{14}$ was performed within 24 hours of the initial endoscopy before starting treatment with omeprazole $40 \mathrm{mg}$ each morning for four weeks in all patients in whom it was clinically indicated.

Parkside Helicobacter
Study Group, Central
Middlesex and
St Mary's Hospitals,
London
R P H Logan
M M Walker
J J Misiewicz
P A Gummett
Q N Karim
J H Baron
Correspondence to:
Dr R P H Logan, Division of
Gastroenterology,
Department of Therapeutics,
University Hospital,
Nottingham NG7 2UH.
Accepted for publication
29 April 1994


Grade of acute gastritis and grade of Helicobacter pylori colonisation in patients before and after treatment with omeprazole $40 \mathrm{mg}$ in the morming

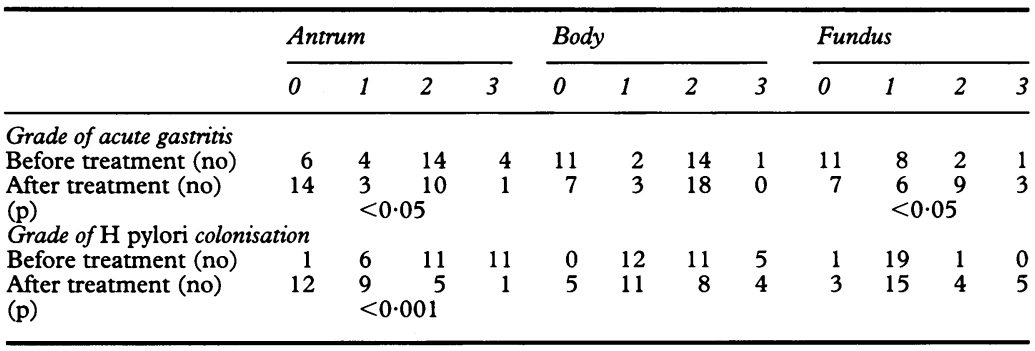

FOLLOW UP

The ${ }^{13} \mathrm{C}$-urea breath test was repeated in the $H$ pylori positive patients after two weeks' treatment with omeprazole. A second endoscopy and a third breath test were completed after a further two weeks' therapy, and a fourth breath test was done two weeks after finishing omeprazole. If this breath test was negative, it was repeated two weeks later to document possible eradication at one month after finishing the drug.

Patients without $H$ pylori were also studied to examine the possibility that overgrowth of other urease producing bacteria might yield a false positive breath test and to act as negative controls.

\section{DETERMINATION OF $H$ PYLORI STATUS}

The presence of $H$ pylori was determined by ${ }^{13} \mathrm{C}$-urea breath test, culture of two antral biopsy specimens on selective and unselective media in microaerobic conditions for up to 10 days, and by histological examination of two specimens from the gastric antrum, corpus, and fundus. Patients were classified as $H$ pylori positive by a positive breath test (excess $\delta$ ${ }^{13} \mathrm{CO}_{2}>5$ per mil) together with either positive antral culture of positive histology from any site.

Clearance of $H$ pylori was defined as a negative breath test (excess $\delta{ }^{13} \mathrm{CO}_{2}<5$ per mil) at the end of treatment, and eradication as a negative breath test one month after the end of treatment. ${ }^{14}$

\section{${ }^{13}$ C-UREA BREATH TEST}

Semiquantitative assessments of the severity of $H$ pylori infection were made with the ${ }^{13} \mathrm{C}$-urea breath test (European standard protocol). ${ }^{14}$ Briefly, a baseline sample of expired breath was obtained before drinking a fatty liquid test meal designed to delay gastric emptying. After 10 minutes, ${ }^{13} \mathrm{C}$-urea (100 mg (99\% pure, Cambridge Isotopes, Boston, USA) in $50 \mathrm{ml}$ of tap water) was swallowed and distributed within the stomach by turning the patient to the left and right decubitus position. Two litre serial breath samples were collected every five minutes into a large reservoir collecting bag, from which a single $20 \mathrm{ml}$ sample (pooled sample) was taken at the end of the test and analysed by mass spectrometry (BSIA, Brentford, London). The results were expressed as excess $\delta{ }^{13} \mathrm{CO}_{2}$ excretion per mil by subtracting the baseline from the pooled sample.

\section{HISTOLOGY}

Biopsy specimens were processed routinely, embedded in paraffin wax, and stained (haematoxylin and eosin, and Gimenez method) for $H$ pylori. In each patient the histologist examined two biopsy specimens at three levels (six sections) from the gastric antrum, body, and fundus and assessed the overall grade (0-3) according to the Sydney system of the activity (numbers of neutrophils) and chronicity (number of lymphocytes) of the gastritis. ${ }^{15}$ For illustrative purposes the means of the overall grades for the three sites of all patients were then calculated. All histological assessments were made by the same experienced histopathologist (MMW), who was unaware of the other results, or of the patient's treatment. Ten biopsy specimens were selected at random for replicate histological examination, in order to assess observer variation.

\section{STATISTICAL ANALYSIS}

The Wilcoxon rank sum test and Spearman's rank correlation coefficient were used for statistical analysis of the histological data; the paired Student's $t$ test was used for ${ }^{13} \mathrm{C}$-urea breath test results.

\section{Results}

Thirty nine patients ( 24 men, median age 48 years, range 16-72 years) with moderate to severe reflux oesophagitis $(n=14)$ or duodenal ulcer unhealed by $\mathrm{H}_{2}$ antagonists $(\mathrm{n}=25)$ entered the study. In 29 of 39 patients $H$ pylori was detected by a positive ${ }^{13} \mathrm{C}$-urea breath test (mean excess $\delta{ }^{13} \mathrm{CO}_{2}$ excretion $=23.0$ per mil), which was confirmed by either positive antral culture $(n=26)$, or positive antral biopsy, or both $(\mathrm{n}=28)$. In all patients $H$ pylori was also present in the corpus biopsy specimens and in 28 of 29 it was present in fundic specimens.

In 10 patients with reflux oesophagitis there was no evidence of $H$ pylori infection on ${ }^{13} \mathrm{C}$-urea breath test (mean (SEM) excess $\delta$ ${ }^{13} \mathrm{CO}_{2}$ excretion $=1.9(0.24)$ per mil), antral culture, or on antral, corpus, and fundic histology.

\section{H PYLORI POSITIVE PATIENTS}

\section{Histology}

Before starting omeprazole $H$ pylori was found in all the biopsy specimens, except those from two patients. One patient had no antral $H$ pylori (but mild chronic antral gastritis and $H$ pylori in the corpus and fundus). Another patient had no fundic $H$ pylori (but mild chronic fundal gastritis and $H$ pylori in the corpus and antrum). The mean density scores for $H$ pylori in the antrum, body, and fundus were $2 \cdot 1,1 \cdot 75$, and 1.04 respectively. The presence of $H$ pylori was often associated with active (presence of neutrophils) antral (26 of 29 ) or corpus gastritis (18 of 28). There were features of chronic inflammation in all the 

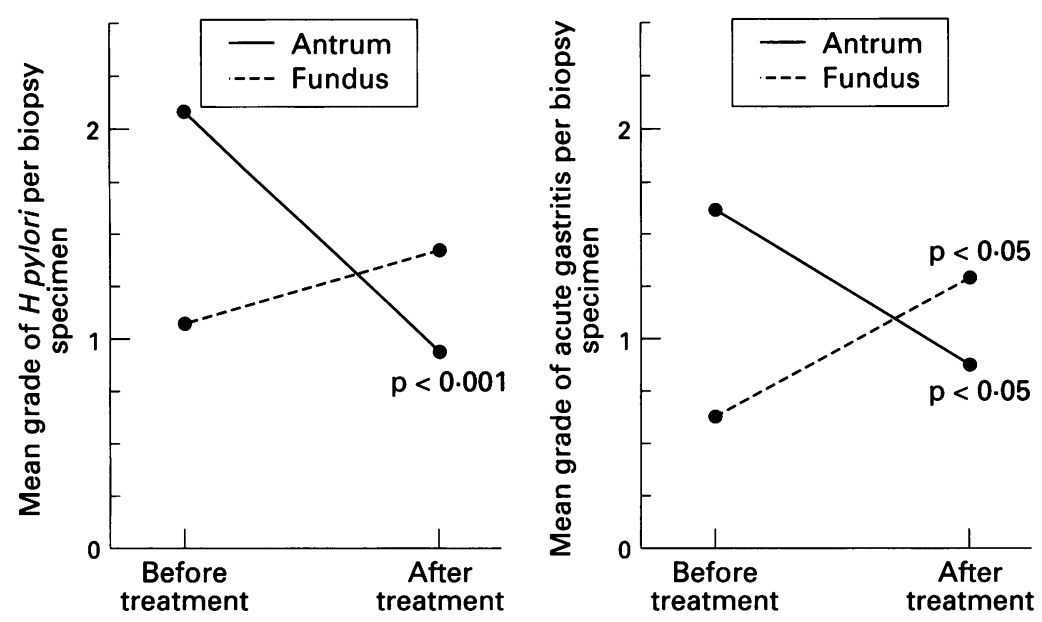

Figure 1: Changes in antral and fundal Helicobacter pylori colonisation and severity of acute antral and fundal gastritis before and after omeprazole, $40 \mathrm{mg}$ mane for four weeks.

remaining, $H$ pylori positive antral, corpus, and fundal specimens.

After four weeks' treatment with omeprazole, $H$ pylori could no longer be detected in the antral specimen of 12 patients. Moreover, in three of these, $H$ pylori could no longer be detected in the corpus specimens, but all three still had organisms in the fundus. In the patients who were $H$ pylori positive before starting treatment, the mean density score of antral $H$ pylori was significantly lower after four weeks' omeprazole $(0.90 \vee 2.1$ before treatment, $p<0.001$, Fig 1) with a similar, but not significant, trend in the corpus $(1.75 v 1.3$, $\mathrm{p}>0.05)$. In contrast, there was a small increase in the density of fundal $H$ pylori (from 1.0 to $1.4, p>0.05)$. These changes in the distribution of $H$ pylori were associated with a decreased mean grade of active antral gastritis (from 1.6 to $0.9, \mathrm{p}<0.05$ ) and an increased mean grade of active fundal gastritis (from 0.6 to $1 \cdot 3, p<0 \cdot 05$, Fig 1 ). The decreased density of antral and corpus $H$ pylori in biopsy specimens correlated with a decreased excess $\delta{ }^{13} \mathrm{CO}_{2}$ excretion measured by the urea breath test (rank Spearman correlation, $r=0.45$, $p<0.05)$. There was no change in the grade of chronic gastritis in the antrum, corpus, or fundus after omeprazole treatment. In one patient, unusual morphological forms of bacteria, not typical of $H$ pylori, were detected after four weeks' omeprazole treatment.

Replicate histological examination assessments of gastritis and $H$ pylori were the same $(n=5)$, or varied by no more than one grade $(n=5)$.

${ }^{13} \mathrm{C}$-urea breath test

The excess $\delta{ }^{13} \mathrm{CO}_{2}$ excretion fell progressively in $H$ pylori positive patients $(\mathrm{n}=29)$ after treatment with omeprazole $40 \mathrm{mg}$ daily. The mean (SEM) excess $\delta{ }^{13} \mathrm{CO}_{2}$ excretion fell from $23 \cdot 0$ $(2 \cdot 1)$ per mil before starting omeprazole to $17 \cdot 2(2 \cdot 1)$ after two weeks' treatment $(\mathrm{p}<0 \cdot 05$, compared with before treatment), and to 15.5 $(2 \cdot 7)$ per mil after four weeks $(p<0 \cdot 25$, compared with two weeks) (Fig 2).The fall in $\delta{ }^{13} \mathrm{CO}_{2}$ at four weeks was closely correlated with the decrease in the semiquantitative histological assessments of $H$ pylori $(\mathrm{r}=0 \cdot 6$, $\mathrm{p}<0.001$ ). In four patients the excess $\delta{ }^{13} \mathrm{CO}_{2}$ excretion fell to $<5$ per mil after four weeks, but in all four the breath test was positive two weeks after finishing omeprazole. In the 12 patients with an antrum histologically cleared of $H$ pylori, the fall in excess $\delta{ }^{13} \mathrm{CO}_{2}$ excretion was more pronounced than in the remainder: the (mean (SEM) excess $\delta{ }^{13} \mathrm{CO}_{2}$ excretion fell from $23.0(2.1)$ to $9.9(4.2)$ per mil, $\mathrm{p}<0.001$ from mean value before treatment), compared with $18.3(3.3)$ per mil in those without antral clearance of $H$ pylori.

Two weeks after finishing treatment the excess $\delta{ }^{13} \mathrm{CO}_{2}$ excretion returned to values before treatment (mean excess $\delta{ }^{13} \mathrm{CO}_{2}$ excretion $=23.0(3.8)$ per mil, $\mathrm{p}>0.5 v$ value before treatment, Fig 2).

\section{H PYLORI NEGATIVE PATIENTS}

In the $H$ pylori negative patients there was no significant change in the excess $\delta{ }^{13} \mathrm{CO}_{2}$ excretion after two weeks' treatment with omeprazole (mean excess $\delta{ }^{13} \mathrm{CO}_{2}=2 \cdot 4(0.37)$ per mil $v 1.9(0.24)$ per mil before treatment, $\mathrm{p}>0 \cdot 25)$.

\section{Discussion}

Omeprazole, given in a dose of $40 \mathrm{mg}$ daily for four weeks, significantly decreased histological evidence of $H$ pylori in the antral mucosa and the corpus, and significantly reduced the activity of antral gastritis. In the fundic mucosa, however, $H$ pylor increased as did the activity of fundic gastritis; but overall the ${ }^{13} \mathrm{C}$-urea breath test results decreased progressively with treatment. The breath test became transiently negative in only four of 29 patients but $H$ pylori was not eradicated by omeprazole in any patient.

These results confirm previous reports

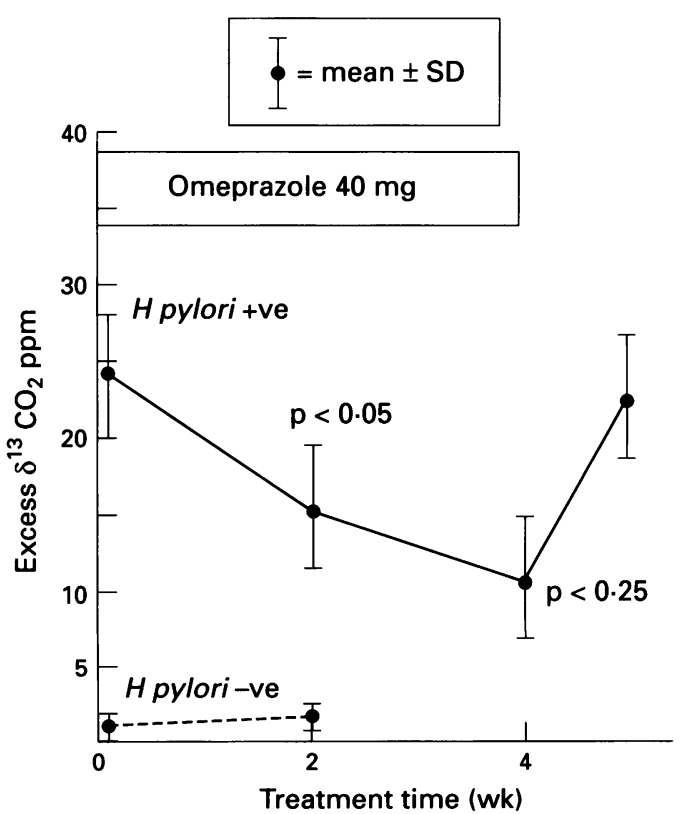

Figure 2: ${ }^{13} \mathrm{C}$-urea breath test results (mean (SD)) in patients who were positive and negative for Helicobacter pylori before, during, and after two and four weeks' omeprazole $40 \mathrm{mg}$ daily. 
that omeprazole suppresses $H$ pylori infection. ${ }^{11} 1217-19$ In a small study using the ${ }^{14} \mathrm{C}$-urea breath test, Bell et al ${ }^{12}$ cleared the organism in half the patients given omeprazole $40 \mathrm{mg}$ for four weeks, while a dose of 20 mg cleared $H$ pylori in only one quarter. No biopsy assessments of $H$ pylori infection were made in this study. After four weeks' treatment with omeprazole $20 \mathrm{mg}$, Daw et al ${ }^{16}$ reported $50 \%$ clearance from the antrum using culture as the criterion (the associated gastritis improved in $54 \%$ of patients), but over half the patients who had been negative on culture at the end of treatment had $H$ pylori in the gastric pits visible on transmission electron microscopy. Similarly, $40 \%$ clearance of antral $H$ pylori was reported after only two weeks of omeprazole $20 \mathrm{mg}$, but histology was used to assess the $H$ pylori status. ${ }^{18}$ Similar results were also reported in a large study dealing with duodenal ulcer patients after four weeks of either ranitidine $150 \mathrm{mg}$ bd or omeprazole 10 or $20 \mathrm{mg}$ daily: in patients receiving omeprazole $20 \mathrm{mg}$ daily, antral $H$ pylori was cleared in $68 \%$ of cases, with a concurrent improvement in the activity of the gastritis. ${ }^{19}$ These changes were not dose related.

The highest $(72 \%)$ clearance of antral $H$ pylori was reported by Vigneri et al after four weeks' omeprazole $40 \mathrm{mg}$ per day. ${ }^{20}$ Thus, clearance of antral $H$ pylori based on biopsy findings occurs in $40 \%$ to $80 \%$ of patients after either two or four weeks' treatment. This effect does not seem to be dose-related, although two retrospective studies have suggested that prolonged treatment might produce higher clearance rates. ${ }^{17}$ Only our study and that of Vigneri et al have documented the increase and shift of $H$ pylori to the fundic mucosa with increased colonisation of this area.

The pathogenic effects of $H$ pylori may depend on the pattern of colonisation, but factors that determine the distribution of the organism within the stomach are unknown. $H$ pylori is most often isolated from the gastric antrum, but loss of normal gastric type epithelium (for example, with gastric antral atrophy or intestinal metaplasia) or the loss of the adherent layer of mucus because of bile reflux is associated with lower levels of antral colonisation. Data from this study suggest that the distribution of $H$ pylori can be changed by omeprazole, so far the only agent shown to influence the distribution of $H$ pylori within the stomach.

One possible explanation for the suppression of $H$ pylori by omeprazole is bacterial overgrowth. In this study neither mucosal biopsy specimens nor gastric juice were assessed microbiologically for bacterial overgrowth because of the inherent problems of accurately reproducing the in vivo microenvironment in vitro. Preliminary data suggest, however, that bacterial overgrowth does not correlate with the suppression of $H$ pylori. $^{21}$ A possible explanation for this observation is that $H$ pylori and other bacteria do not share the same habitat: $H$ pylori is generally found beneath the mucus layer or in the gastric pits, while other bacteria colonise the gastric lumen and surface mucus. In addition, loss of antral $H$ pylori in patients with atrophic antral gastritis (but in whom $H$ pylori persists in the corpus) is seldom associated with bacterial overgrowth (J Wyatt, personal communication).

Omeprazole and lansoprazole are potent inhibitors of $H$ pylori in vitro, with minimum inhibitory concentrations that compare favourably with bismuth salts. ${ }^{22-24}$ After the preliminary results of our study had been reported, Bugnoli et al discovered that omeprazole was a powerful inhibitor of $H$ pylori urease. Although these data may seem to explain our findings, mutant urease negative $H$ pylori and $H$ mustelae were also inhibited by omeprazole. In addition inhibition of urease is an ineffective treatment for $H$ mustelae, ${ }^{25}$ which suggests that omeprazole's urease inhibition alone does not account for our findings.

Although omeprazole heals duodenal ulcers more rapidly than $\mathrm{H}_{2}$ antagonists do, ${ }^{19}$ the incidence of recurrence in the absence of maintenance treatment is similar. ${ }^{26}$ Duodenal ulcer healing rates are related to the extent of acid suppression. ${ }^{27}$ It has also been shown that duodenal ulcer healing rates may increase when $\mathrm{H}_{2}$ antagonists are combined with anti- $\mathrm{H}$ pylori treatment. ${ }^{28}$ It is possible, therefore, that more rapid duodenal ulcer healing with omeprazole may depend on suppression of $H$ pylori as well as greater inhibition of gastric acid. Because omeprazole does not eradicate $H$ pylori, the incidence of duodenal ulcer recurrence after initial healing with omeprazole is similar to those recorded with other antisecretory agents. ${ }^{26}$

We have shown that during treatment with omeprazole, $H$ pylori may be suppressed sometimes simulating clearance of the antrum and corpus, or both, but with relapse of $H$ pylori after the end of treatment. This effect of omeprazole considerably impairs the sensitivity of antral biopsy tissue for detecting $H$ pylori in patients who are taking this drug. The practical consequences of this observation are that if breath tests are not available biopsies should also be taken from the corpus and fundus in order to determine if $\mathrm{H}$ pylori is still present in the stomach. In addition for patients unable to temporarily stop treatment with omeprazole, a negative breath test result should be interpreted with caution.

How omeprazole suppresses $H$ pylori is not clear. We hypothesise that our findings may be due to $H$ pylori's chemotaxis for $\mathrm{H}+$, however, further studies of the relationship between $\mathrm{H}+, H$ pylori, and the role of urease are needed.

The authors thank the endoscopy staff at the Central Middlesex and St Mary's Hospitals for help with this study. Dr R Logan was supported by a grant from Glaxo Group Research.

An abstract of this study was presented at the European Digestive Diseases Week in Amsterdam in September 1991. Rauws EA, Langenberg W, Houthoff $\mathrm{HJ}$, Zanen $\mathrm{HC}$,
Tytgat GNJ. Campylobacter pyloridis-associated chronic Tytgat GNJ. Campylobacter pyloridis-associated chronic active antral gastritis. A prospective study of its prevalence and the effects of antibacterial and antiulcer treatment. Gastroenterology 1988; 94: 33-40.

2 Rauws EAJ, Tytgat GNJ. Cure of duodenal ulcer with eradication of Helicobacter pylori. Lancet 1990; 335: 1233-5.

3 Axon AR. Duodenal ulcer: the villain unmasked? $B M \mathcal{F}$ 1991; 302: 919-21 
4 Eaton KA, Brooks CL, Morgan DR, Krakowka S. Essential role of urease in pathogenesis of gastritis induced by Helicobacter pylori in gnobiotic piglets. Infect Immun 1991; 59: 2470-5.

5 Mobley HLT, Hausinger RP. Microbial ureases: significance, regulation and molecular characterisation. Microbiol Rev 1989; 53: 85-108.

6 Maton PN. Omeprazole. N Engl f Med 1991; 324: 965-75.

7 Mainguet P, Delmee M, Debongnie J-C. Omeprazole, Campylobacter pylori and duodenal ulcer. Lancet 1989; ii: 389-90.

8 Ghelani AM, Hale S, Coleman H, Radziwonik $H$, Robertson C, Atkinson M. Lack of in vitro activity of omeprazole against Campylobacter pylori. 7 Clin Pathol omeprazole against

9 Biasco G, Miglioli M, Barbara L, Corinaldesi R, Di Febo G. Omeprazole, Helicobacter pylori, gastritis and duodenal ulcer. Lancet 1989; ii: 1403 .

10 Tessaro P, Di Mario M, Rugge M, Baffa R, Pasqualetti P, Vio A, et al. Efficacy of omeprazole in eradicating Helicobacter pylori from the gastric mucosa. Eur $\mathscr{f}$ Gastroenterol Hepatol 1990; 2 (1): S117-8

11 Sharp J, Logan RPH, Walker MM, Gummett PA, Misiewicz J, Baron JH. Effect of omeprazole on Helicobacter pylori. Gut 1991; 32: A565.

12 Weil J, Bell DG, Powell K, Morden A, Harrison G, Gants PW, et al. Omeprazole and Helicobacter pylori: temporary suppression rather than true eradication. Alimentary suppression rather than true eradication.

13 Weller IVD, Williams CB, Jeffries DJ, Leicester RJ, Gazzard BG, Axon ATR, et al. Cleaning and disinfection of equipment for gastrointestinal flexible endoscopy: interim recommendations of a Working Party of the British Society of Gastroenterology. Gut 1988; 29: 1134-51.

14 Logan RPH, Dill S, Bauer FE, Walker MM, Hirschl AM, Gummett $\mathrm{PA}$, et al. The European ${ }^{13} \mathrm{C}$-urea breath test for the detection of Helicobacter pylori. European fournal of Gastroenterology and Hepatology 1991; 3: 915-21.

15 Misiewicz JJ. The Sydney system: a new classification of gastritis. $\mathcal{F}$ Gastroenteral Hepatol 1991; 6: 207-52.

16 Daw MA, Deegan P, O'Morain C. The effect of omeprazole on Helicobacter pylori and associated gastritis. Alimentary Pharmacology and Therapy 1991; 5: 435-39.

17 Stolte M, Bethke B. Elimination of Helicobacter pylori under treatment with omeprazole. Z Gastroenterol (Verh) 1990; 28: $271-4$.
18 Arachimandritis C, Tjivras M, Davaris P, Fertakis A. Effect of omeprazole of $\mathrm{H}$ pylori after 2 weeks of treatment. Italian fournal of Gastroenterology 1991; 23: 357-8.

19 Hui WM, Lam SK, Ho J, Lai CL, Lok ASF, Ng MMT, et al. Effect of omeprazole on duodenal ulcer-associated antral gastritis and Helicobacter pylori. Dig Dis Sci 1991; 36: 577-82.

20 Vigneri S, Termini R, Scialabba A, Pisciotta G, Di Mario F. Omeprazole therapy modifies the gastric localisation of Helicobacter pylori. Am $\mathcal{f}$ Gastroenterol 1991; 86: 1276.

21 Fraser R, Thorens J, Froelich F, Gonvers JJ, Bille J, Blum A, et al. Relationship between Helicobacter pylori infection and gastric and duodenal bacterial overgrowth. and gastric and duodenal

22 Iwahi T, Satoh H, Nakao M, Iwasaki T, Yamazaki T, Kubo $\mathrm{K}$, et al. Lansoprazole, a novel benzimidazole proton pump inhibitor, and its related compounds have selective activity against Helicobacter pylori. Antimicrobial Agents and Chemotherapy 1991; 35: 490-6.

23 Bugnoli M, Bayeli PF, Rappuoli R, Pennatini C, Figura N, Crabtree JE. Inhibition of Helicobacter pylori urease by omeprazole. European fournal of Gastroenterology Hepatology 1993; 5: 683-5.

24 Nagata $K$, Satoh $H$, Iwahi T, Shimoyama T, Tamura $T$. Potent inhibitory action of the gastric proton pump Potent inhibitory action of the gastric proton pump
inhibitor lansoprazole against urease activity of inhibitor lansoprazole against urease activity of Helicobacter pylori: unique action selective for $\mathrm{H}$ pylori cells. Antim

25 McColm AA, Bagshaw JA, O'Malley CFO. Development of a ${ }^{14} \mathrm{C}$-urea breath test in ferrets colonised with Helicobacter mustelae: effects of treatment with bismuth, antibiotics and urease inhibitors. Gut 1993; 34: 181-6.

26 Schiller KFR, Axon ATR, Carr-Locke DL, Cockel R, Donovan IA, Edmonstone WM, et al. Duodenal ulcer recurrence after healing with omeprazole or cimetidine treatment: a multicentre study in the UK. Gut 1989; 30: A1490.

27 Hunt RH, Howden CW, Jones DB, Burget DW, Kerr GD. The correlation between acid suppression and peptic ulcer healing. Scan $\mathcal{F}$ Gastroenterol 1986; 21 (suppl 125):

28 Graham DY, Ginger M, Lew PA-C, Evans DG, Evans DJ, Klein PD, et al. Effect of triple therapy (antibiotics plus bismuth) on duodenal ulcer healing. Ann Intern Med 1991; 115: 266-9. 